\title{
THE ECONOMIC ESSENCE OF CURRENCY RISK OF A COMMERCIAL BANK
}

\author{
C 2019 Borisova Alexandraa Evgenevna \\ Student \\ (c) 2019 Zhegalova Elena Valerevna \\ Candidate of Economics, Associate Professor \\ (c) 2019 Kuznetcova Alina Olegovna \\ Student \\ Samara State University of Economics \\ E-mail: crashedinatunebox@gmail.com
}

Keywords: commercial banks, risks, exchange rate risks, operational currency risk, translational currency risk, economic currency risk.

The paper presents the definition of foreign exchange risk in commercial banks. Basic methods for currency risk management in commercial banks are suggested.

УДК 311.312

Код РИНЦ 83.00 .00

\section{СТАТИСТИЧЕСКИЙ АНАЛИЗ СТРУКТУРЫ МАЛОИМУЩЕГО НАСЕЛЕНИЯ В РОССИЙСКОЙ ФЕДЕРАЦИИ}

\author{
() 2019 Букина Анастасия Александровна \\ магистрант \\ (c) 2019 Чистик Ольга Филипповна \\ доктор экономических наук, профессор \\ Самарский государственный экономический университет \\ E-mail: nastnk97@yandex.ru, yurijchistik@yandex.ru
}

Ключевые слова: бедность, малоимущие домашние хозяйства, прожиточный минимум, выборочные обследования, финансовое и материальное положение.

Была проанализирована категориальная структура и дана оценка финансового и материального положения малоимущего населения России.

Бедность является острой общественной проблемой. Бедность влияет на здоровье, уровень образования и культуры наших граждан, она ведет к понижению уровня и качества жизни, росту преступности.

Бедность следует рассматривать как состояние отсутствия необходимых ресурсов для обеспечения удовлетворительного образа жизни ${ }^{1}$. Бедность исследовалась рядом авторов 2,3,4. 
Существенным аспектом исследования проблемы бедности выступает категориальный состав бедных. Большая доля бедного населения относится к городскому (63\%), при этом на протяжении всего анализируемого периода происходило относительное увеличение городской бедности.

Исходя из распределения малоимущего населения по возрасту, можно заключить, что за анализируемый период большую долю занимает население трудоспособного возраста. Меньшую долю занимают пенсионеры, и в 2017 г. она составила 11,4%. Происходит постепенное уменьшение доли пенсионеров к 2017 году. Данное явление связано с необходимостью социального обеспечения прежде всего самых незащищённых, то есть лиц пенсионного возраста.

В рассматриваемый период происходит увеличение экономической бедности. Так доля занятого в экономике населения среди малоимущего населения за исследуемый период росла и в 2017 достигла 61,6\%.

Происходит сокращение показателя бедности с 40\% до 30\% среди незанятых в экономике граждан в возрасте от 15 до 72 лет, при этом удельный вес малоимущих безработных остается невысоким (2,6 \% в 2017 г.).

Структура получателей пособий среди малоимущего населения за 2013 и 2016 годы представлена на рис. 1.

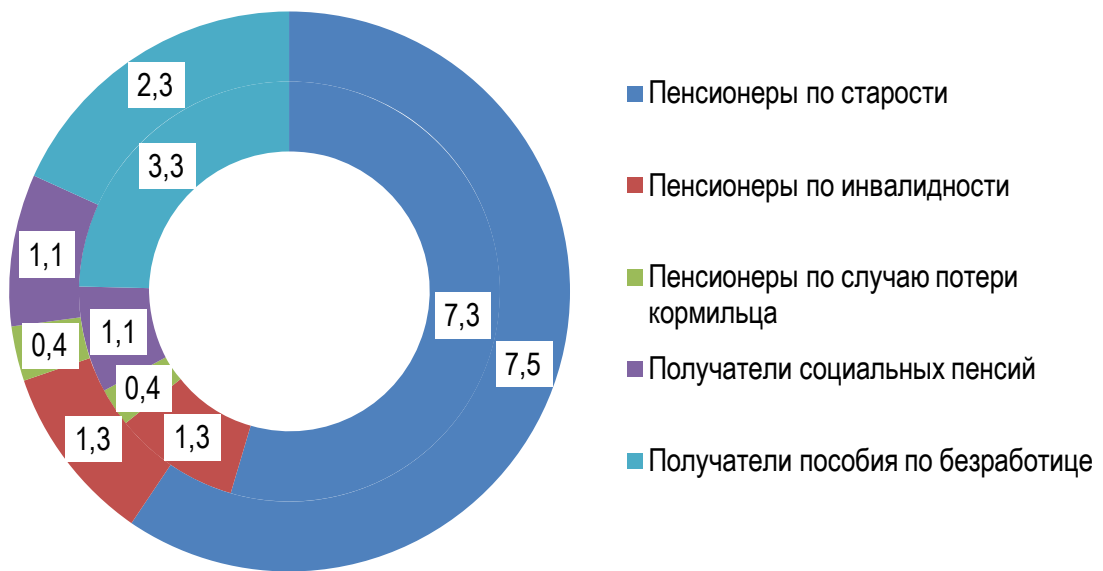

Рис. 1. Доля пенсионеров и безработных в составе малоимущего населения за 2013 и 2016 годы, \%

Из рисунка следует, что большую долю в 2013 и 2016 гг. среди малоимущих пенсионеров и безработного населения занимают пенсионеры по старости, следует отметить, что к 2016 году их доля увеличилась на 0,2 п.п.

Наименьшая доля приходится на пенсионеров по случаю потери кормильца, что составляет 0,4 \% как в 2013, так и в 2016 году. Следует заметить незначительное уменьшение доли получателей пособия по безработице на 1 п.п. к 2017 году.

На основе материалов выборочных обследований домашних хозяйств России была дана оценка финансового положения малоимущих домашних хозяйств (рис. 2). 


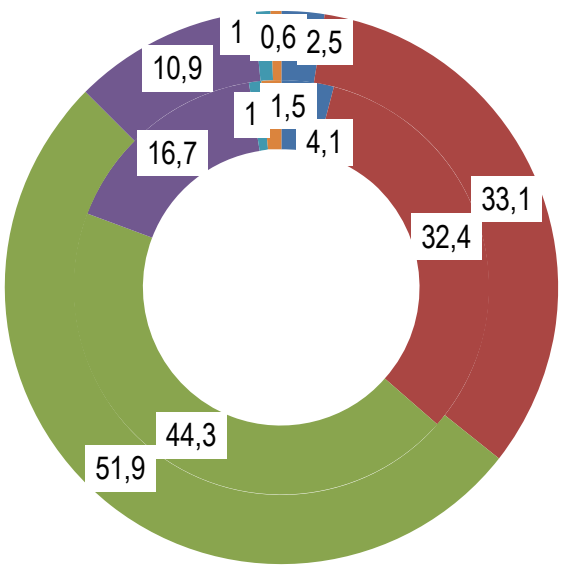

- не хватает денег даже на еду

- затруднительно покупать одежду и оплачивать ЖКХ

- не могут позволить покупку товаров длительного пользования

- не хватает денег на покупку автомобиля, квартиры, дачи

средств достаточно, чтобы купить все, что считают нужным

ватруднились ответить

Рис. 2. Распределение домашних хозяйств по оценке финансового положения за 2013 и 2017 годы, \%

Большая доля опрошенных не может позволить покупку товаров длительного пользования, причем к 2017 году она увеличилась на 7,6 п.п. Меньшую долю среди опрошенных занимают респонденты, которые считают, что могут купить все, что нужно, их доля составляет 1\% от общей совокупности опрошенных как в 2013 так и в 2017 году.

В 2017 году более трети домашних хозяйств испытывают затруднения в покупке одежды и оплате жилищно-коммунальных услуги трем процентам не хватает средств на питание. Эти домохозяйства бесспорно принадлежат к малоимущему слою населения.

На рис. 3 можно видеть, что большинство домохозяйств имеет среднее материальное положение $(64,1 \%)$, незначительная доля обладает очень хорошим материальным положением (0,2\%), 25,5\% из всей совокупности обладает плохим положением и только $0,4 \%$ не смогли его определить. Таким образом, большинство бедного населения испытывает необходимость в улучшении своего материального положения.

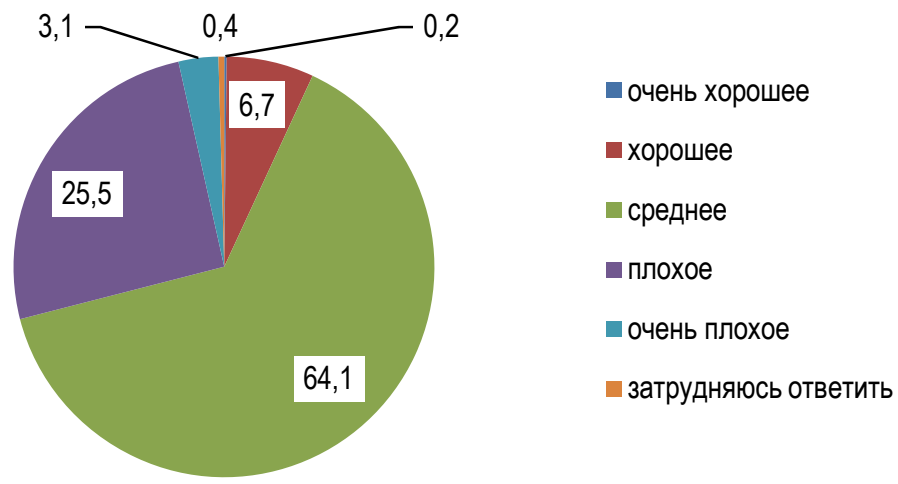

Рис. 3. Распределение домашних хозяйств по оценке материального положения в 2017 году, \% 
Для оценки структурных различий в распределении населения по величине среднедушевых денежных доходов за 2013 и 2017 годы ${ }^{5}$ был применен индекс Рябцева:

$$
\mathrm{IR}=\sqrt{\frac{\sum\left(d_{1 i}-d_{0 i}\right)^{2}}{\sum\left(d_{1 i}+d_{0 i}\right)^{2}}}=0,110 .
$$

Расчетные данные представлены в таблице. Оценивание различий структур выполнено по предложенной профессором Чистик шкале меры структурных различий. По полученным расчетам и шкале меры различий можно сделать вывод о низком уровне структурных различий в рассматриваемом периоде.

Расчетная таблица для определения индекса Рябцева

\begin{tabular}{|c|c|c|}
\hline Группы населения по средним & $\mathbf{2 0 1 3}$ & $\mathbf{2 0 1 7}$ \\
\cline { 2 - 3 } доходам в месяц & (d1-d0) & $\mathbf{( d 1 + d 0 )}^{\mathbf{2}}$ \\
\hline Первая & 21,16 & 231,04 \\
\hline Вторая & 7,29 & 320,41 \\
\hline Третья & 5,76 & 665,64 \\
\hline Четвертая & 1,44 & 864,36 \\
\hline Пятая & 1,21 & 1288,81 \\
\hline Шестая & 13,69 & 1806,25 \\
\hline Седьмая & 5,76 & 225,00 \\
\hline Восьмая & 13,69 & 334,89 \\
\hline Всего & 70,00 & 5736,40 \\
\hline
\end{tabular}

Анализ структуры малоимущего населения в РФ показал, что бедность обусловлена преимущественно экономическими и демографическими причинами.

Проблеме бедности стоит уделить особое внимание. Сокращение числа бедных и предупреждение его увеличения должно стать вектором экономической политики. А для того, чтобы снизить её уровень необходимо увеличить доходы основной части населения на основе экономического роста.

1 Чистик О.Ф. Статистический анализ уровня жизни малообеспеченных слоев населения России [Текст] /О.Ф.Чистик //Вестник Самарского государственного экономического университета. Самара. - 2011. - № 4 (78). - С. 103-107.

2 Абрамова, О.С. Структурный и каузальный анализ региональной бедности [Текст] / О.С. Абрамова // Вестник Самарского государственного экономического университета. - Самара. 2014. - № 4 (114). - С. 31-37.

${ }^{3}$ Об уровне бедности населения Самарской области [Текст] : аналит. зап. / Самарастат. Самара.- 2014. - 27 c.

${ }^{4}$ Николаев, И.А. Бедность в России: экономический анализ: аналит. доклад [Текст] / И.А. Николаев, Е.В. Марушкина ; ФБК, Департамент стратегического анализа. - М., 2005. - 51 с.

${ }^{5}$ Росстат [Электронный ресурс]. - М., 2018. - Режим доступа: http://www.gks.ru/. 


\title{
STATISTICAL ANALYSIS OF THE STRUCTURE OF THE POOR POPULATION IN THE RUSSIAN FEDERATION
}

\author{
(C) 2019 Bukina Anastasia Alexandrovna \\ graduate student \\ (C) 2019 Chistik Olga Filippovna \\ Doctor of Economics, Professor \\ Samara State University of Economics \\ E-mail: nastnk97@yandex.ru, yurijchistik@yandex.ru
}

Keywords: poverty, poor households, subsistence level, sample surveys, financial and material situation, Ryabtsev index.

The structure of the poor was analyzed for various categories, and an assessment was made of the financial and material situation of the poor.

УДК 311.313

Код РИНЦ 06.35.33

\section{МОДЕЛИРОВАНИЕ МИГРАЦИОННОГО ПРИТОКА НАСЕЛЕНИЯ В САМАРСКОЙ ОБЛАСТИ КАК ПОКАЗАТЕЛЯ МИГРАЦИОННОЙ ПРИВЛЕКАТЕЛЬНОСТИ МУНИЦИПАЛЬНЫХ РАЙОНОВ}

\author{
(c) 2019 Бурова Наталья Алексеевна* \\ студент \\ Самарский государственный экономический университет \\ E-mail: burova_19981998@mail.ru
}

Ключевые слова: муниципальные районы, миграция, приток, корреляционнорегрессионный анализ, моделирование числа прибывших.

Статья посвящена изучению факторов, влияющих на миграционную привлекательность муниципальных районов Самарской области с помощью корреляционно-регрессионного анализа миграционного притока.

В Самарской области, как и в Российской Федерации в целом, сохраняется тенденция убыли населения. Для того, чтобы снизить данный негативный эффект, необходимо проведение ряда мероприятий, способствующих улучшению данной ситуации.

Одним из возможных способов является увеличение миграционного притока населения. Поэтому миграционная политика органов местного самоуправления Самарской области может быть направлена на привлечение новоселов и закрепление уже живуще-

* Научный руководитель - Проскурина Наталья Вячеславовна, кандидат экономических наук, доцент. 